\title{
Does sentiment matter for stock market returns? Evidence from a small European market
}

\author{
Carla Fernandes $^{\dagger}$ \\ University of Aveiro \\ Paulo Gama ${ }^{\ddagger}$ \\ University of Coimbra/ISR-Coimbra \\ Elisabete Vieira ${ }^{*}$ \\ University of Aveiro/GOVCOPP
}

March, 2010

\footnotetext{
† Address: ISCA-UA, R. Associação Humanitária dos Bombeiros de Aveiro, Apartado 58, 3811-902 Aveiro, Portugal. Phone: +351 234380 110. Fax: +351 234380 111. E-mail: carla.fernandes@ua.pt.

‡ Address: Faculdade de Economia, Av. Dias da Silva, 165, 3004-512 Coimbra, Portugal. Phone: +351 239790 523. Fax: +351 239403 511. E-mail: pmgama@fe.uc.pt.

* Address: ISCA-UA, R. Associação Humanitária dos Bombeiros de Aveiro, Apartado 58, 3811-902 Aveiro, Portugal. Phone: +351 234380 110. Fax: +351 234380 111. E-mail: elisabete.vieira@ua.pt.
} 


\title{
Does sentiment matter for stock market returns? Evidence from a small European market
}

\begin{abstract}
An important issue in finance is whether noise traders, those who act on information that has no value, influence prices. Recent research indicates that investor sentiment affects the return distribution of a few categories of assets in some stock markets. Other studies also document that US investor sentiment is contagious.

This paper investigates whether Consumer Confidence (CC) and the Economic Sentiment Indicator (ESI) - as proxies for investor sentiment - affects Portuguese stock market returns, at aggregate and industry levels, for the period between 1997 to 2009. Moreover the impact of US investor sentiment on Portuguese stock market returns is also addressed.

We find several interesting results. First, our results provide evidence that consumer confidence index and ESI are driven by both, rational and irrational factors. Second, ESI is significantly negative related to stock returns. Sentiment negatively forecasts aggregate stock market returns, but not all industry indices returns. Finally, we don't find a contagious effect of US investor sentiment in Portuguese market returns.
\end{abstract}

JEL classification: G10, G11.

Keywords: Behavioural Finance, Investor Sentiment, Industries. 


\section{Introduction}

A widely discussed issue in finance is the extent to which asset prices reflect fundamental value. According to Fama (1970), information flow is the only determinant of movements in stock market prices and these reflect the fundamental value of the underlying assets.

Thus, in accordance with the efficient markets hypothesis, changes in asset prices result from a rapid readjustment of their value motivated by the investor's transactions in response to changes in the set of information. However, in the market two types of investors coexist, noise traders and information traders, also known as arbitrageurs or rational speculators. Arbitrageurs formulate completely rational expectations about security returns and their transactions ensure that prices converge to fundamental value. In contrast, the opinions and transaction patterns of the noise traders are susceptible to systematic errors and biases. The decisions of these agents are based more on psychological factors and sentiment than on investment management principles.

According to Baker and Wurgler (2007) investor sentiment represents a belief about future cash flows and risk which is not justified by economic and financial information. Brown and Cliff (2004) considered that "sentiment represents the expectations of market participants relative to a norm: a bullish (bearish) outlook means investors expect returns to be above (below) average, whatever "average" may be" (p. 2).

In the last decades a number of researchers in the field called behavioural finance have been interested in investigating the extent to which the noise traders, who act on information that has no value, influence prices. For example, Shleifer and Summers (1990) highlight the role of investor sentiment and limits of arbitrage in asset pricing. In their approach, the authors consider two assumptions: first, that some investors are not completely rational and their demand for risk assets is affected by beliefs or sentiment not justified by the information about fundamentals. Second, that arbitrage - which they define as the transactions conducted by rational investors - is risky and therefore limited. The two assumptions jointly imply that changes in investor sentiment are not fully considered by arbitrageurs and thus affect security returns.

Also Hughen and McDonald (2005) refer that the existence of significant arbitrage costs impedes the trading activity of rational investors. According to these authors: "The ability of arbitrageurs is limited if sentiment is cross-sectionally correlated and they face the risk of continued movements away from fundamental values" (p. 281). These conditions form the basis of DeLong et al. (1990) noise trader model, which shows that the transactions motivated by the sentiment may cause price deviations from fundamental value. 
Qiu and Welch (2006) also consider that sentiment can influence asset prices under two conditions: the assets are predominantly held by noise traders and transaction costs are high enough to avoid arbitrage.

Baker and Wurgler (2006) refer that mispricing is a combination of two factors: change in irrational trader sentiment and limits of arbitrage faced by rational investors.

Thus, several researchers have investigated the effect of investor sentiment in asset pricing patterns, such as: DeBondt and Thaler (1985), DeBondt (1998), Fisher and Statman (2000), Shefrin (2001), Brown and Cliff (2005) Baker and Wurgler (2006 and 2007), Lemmon and Portniaguina (2006), Wang, Keswani and Taylor (2006) and Schmeling (2009), among others.

Our study investigates whether investor sentiment predicts future aggregate stock market returns and industrial indices returns in Portugal, between September 1997 and April 2009, and if the relationship between sentiment and expected returns is significantly negative, even after controlling for macroeconomic factors.

Additionally, we investigate whether US investor sentiment affects the Portuguese stock market, at aggregate and industry levels.

Our study has empirical and theoretical motivations. Firstly, most of studies focus on the major capital markets, mainly the U.S. market. Secondly, many of the studies until now investigate the impact of sentiment on certain categories of assets or portfolios. There are only a small number of studies whose analysis focuses on the aggregate market or on specific sectors, which may contribute to empirical evidence of the overall impact of sentiment.

Theoretically, most researchers in behavioural finance suggest the strong presence of noise traders in the stock market with sentiment correlated and limits on arbitrage as conditions that can lead sentiment to influence asset prices. So, our choice of the Portuguese market will make it possible to test some of these assumptions.

According to Chui, Titman and Wei (2010) a collectivist culture is a driver of investors' tendency to herding, which in the capital market can lead to the possibility of noise traders' errors being correlated. In the context of the literature on the effects of sentiment contagion, Chang, Faff e Hwang (2009) state that if investors herd, then there will be stronger sentiment contagion. According to Hofsted (2001) Portugal has high degree of collectivism. These ideas also motivated our study.

La Porta, et al. $(1997,1998)$ state that the laws that protect investors against expropriation by insiders affect the propensity of retail investors to participate in equity markets. If there is low participation by such investors in the market, there will be less tendency to speculation and thus for the influence of the sentiment. The authors also explored the idea that companies in countries with poor investor protection had more concentrated ownership of their shares. They found that countries with legal systems based on French-civil-law had the greatest ownership concentration. 
According to La Porta, et al. (1998) Portugal was among the countries with high concentration of ownership. On the one hand, the large presence of institutional investors can lead to a situation where the market is less prone to the influence of sentiment. On the other hand, institutional investors face limits to arbitrage, as discussed above. These ideas also motivated our study.

Barberis and Shleifer (2003), Peng and Xiong (2006) show that investors tend to categorize assets into groups, in particular, into industries. Jame and Tong (2009) reported that investment decisions may involve an industry wide component. This implies that industry level reallocations, by small investors, should occur with greater intensity than reallocations across stocks grouped randomly. They found that the retail investors' trades were correlated across industries. These also motivated our study at industry effects.

We found, first, that the sentiment had a negative impact on future market returns for forecast horizons of 1 to 12 months, which in general is consistent with the theoretical considerations of the impact of the noise trader behaviour. Secondly, in our industry analysis, we found that PSI Telecommunications was the index that showed a more similar behaviour to the aggregate market. For the other industry indices sentiment just had some predictive power on the future returns of the PSI Utilities and PSI Technology for forecasting horizons longer than 1 month. Finally, we don't found a contagious effect of US investor sentiment in Portuguese market and industry returns.

The rest of this paper is structured as follows: the next section reviews some of the existing relevant literature on the sentiment effect and discusses some of the sentiment measures used in the literature; section 3 describes the methodology; section 4 presents the main results and the robustness analysis; finally, section 5 presents some concluding remarks.

\section{Literature review}

In section 2.1 we analyze relations between sentiment and markets behaviours both at a theoretical level and empirical evidence. In section 2.2 we discuss different proxies to the sentiment variable. 


\subsection{Behavioural effects}

According to researchers in behavioural finance, the presence of noise traders in markets with correlated behaviour and the limits of arbitrage may be considered a possible explanation for the existence of certain price anomalies.

According to Andrikopoulos (2007), under-reaction and overreaction represent two of the assumptions that partially explain the price anomalies. Individuals' tendency to overreact or underreact in some circumstances derives from conservatism ${ }^{2}$ and representativeness ${ }^{3}$ heuristic [Kahneman, Slovic and Tversky (1982) Daniel, Hirsheifer and Subrahmanyam (1998), Kaestner (2006)].

Under the representativeness heuristic, investors will consider a series of positive firm performances as representative of continuous growth potential, and ignore the possibility that this performance may be random. This sometimes leads to excessive optimism and overvaluation of firm announcements.

DeBondt and Thaler $(1985,1987,1989)$ argued that investors in the face of what they learn based on experience, become too pessimistic about the past extreme losers, and too optimistic about the past extreme winners, leading the former to become under-valuated and the latter overvaluated.

Shefrin and Statman (1997) concluded that the agents surveyed in their study expected that securities of companies with a winning past would continue as winners, while the opposite occurred in respect of securities of companies with a losing past. These facts have led to the tendency of analysts to recommend the purchase of securities of companies with winning pasts.

DeBondt and Thaler (1985) also confirmed the overreaction hypothesis.

According to Andrikopoulos (2007), overreaction and under-reaction to new information can be viewed as a combination of the inability for investors to correctly distinguish the short and long run [Jegadeesh and Titman (1993)] and the excessive optimism of investors caused by biased selfattribution. ${ }^{4}$

DeBondt (1998) showed that investors exhibited an excessive optimism and overconfidence, were not interested in diversification and rejected the positive relationship between return and risk.

\footnotetext{
${ }^{2}$ According to Andrikopoulos (2007): "Conservatism, refers to the condition where investors are subconsciously reluctant to alter their beliefs in the face of new evidence. The main impact of this bias in investment decision making is that even if investors' beliefs are changed in the light of new information, the magnitude of that change is relatively low in terms of what it should be under strictly rational conditions" (p. 9).

${ }^{3}$ According to Andrikopoulos (2007): "Representativeness heuristic is the illusion of seeing patterns in a random walk" (p.10).

${ }^{4}$ Self-attribution occurs when individuals attribute the success to their abilities and failures to luck.
} 
According to behavioural finance authors, psychological factors may cause changes in asset prices not justified by fundamentals, if the sentiment is cross-sectionally correlated and if there are limits to arbitrage. Shefrin (2001), for example, considers that sentiment is a reflection of the aggregate trader's errors. "The degree to which an individual trader's error process affects market sentiment depends on the size of the trader's trades" (p. 44).

According to Fama (1998), irrational investors transact randomly, so the transactions probably cancel out. Furthermore, the arbitrage process and competition between arbitrageurs can lead to the accumulation of losses and consequent wealth losses for the irrational investors encouraging them to leave the market. Thus, according to these arguments, the market will tend to equilibrium.

However, arbitrage is riskless only if there are securities in the market that are perfect substitutes, otherwise the elimination of mispricing by arbitrageurs is limited.

Moreover, according to Shleifer and Summers (1990), there are two risk types that limit arbitrage: fundamental risk and risk associated with noise trading.

Another limit to arbitrage is related to the investment horizon, which is not unlimited. Arbitrage often involves lending securities or money, which leads to paying out compensation to creditors. This may become too expensive in long run horizons.

Shleifer and Summers (1990) argue that although some changes in demand for securities by the investors who are completely rational, others reflect changes in expectations or sentiment and therefore are not fully justified by fundamental information. These changes may be in response to pseudo-signals which investors believe contain information about future performance, but this type of information is not incorporated in a completely rational model.

However, several strategies based on popular models or false signals are correlated, leading to aggregate changes in demand, particularly because biases in judgments and information analysis tends to be common and persistent among investors, like overconfidence and investment decisionmaking based on the representativeness heuristic, which can lead to overreaction to information.

According to Shleifer and Summers (1990) the noise traders tend to be on average more aggressive than arbitrageurs either because they are overly optimistic or overconfident. Thus, they take on a higher level of risk. If the risk-taking is rewarded by the market, the noise traders can earn high returns, thereby acquiring even more confidence, continuing to trade thusly. According to the authors, the risk rewarded by the market does not necessarily have to be fundamental. It can also be the risk associated with the unpredictability of the noise traders' expectations. When the noise traders earn high returns, other investors tend to imitate them, ignoring the fact that the gains obtained involved a higher level of risk and have essentially been the result of luck. This imitation brings to the market more application of money in strategies based on noise, because under these conditions investors tend to attribute the gains to their skills and not to luck. 
Moreover, while some investors may leave the market, other new noise traders enter, and even those who have left market in the past may return.

Thus, changes in demand motivated by noise traders may be relevant even in the long run.

Although there is not a consensus on the influence of investor sentiment in stock markets, several studies have documented that sentiment influences returns and valuation of assets [Fisher and Statman (2000), Brown and Cliff (2005), Baker and Wurgler (2006, 2007), Lemmon and Portniaguina (2006), Schmeling (2009)], volatility [Wang, Keswani and Taylor (2006)], the practices of information disclosure and market reaction to announcements [Bergman and Roychowdhury (2008), Mian and Sankaraguruswamy (2008)].

Fisher and Statman (2000) analyzed the relationship between sentiment and future returns as well as the relationship between changes in sentiment and future returns.

The authors, in their study considered three groups of investors: Wall Street strategists (such as large investors), writers of investment newsletters (medium investors) and individual investors (as small investors). They concluded that there was a negative and statistically significant relationship between the sentiment level of individual investors and Wall Street strategists and returns in the following month on high capitalization stocks.

Shefrin (2001) has demonstrated that stock price variation could be broken down into two stochastic processes, one pertaining to fundamentals and the other to sentiment.

Brown and Cliff (2005) used survey data on investor sentiment. These data are from Investor's Intelligence (II) (which tracks the number of market newsletters that are bullish, bearish or neutral) and showed that sentiment affected asset pricing. They concluded that the market was over valuated during periods of optimism.

The results of Brown and Cliff (2005) showed that in large companies or companies with a low book-to-market ratio sentiment was significant in predicting future returns in 1, 2 and 3-year time horizons. However, small stocks seem to be less influenced by sentiment. One possible explanation for this result is that the newsletters contain forecasts for the market as a whole. So, this data did not allow the analysis and conclusion that small stocks are more prone to the influence of the sentiment to be made.

Brown and Cliff (2005) refer that their results support the important conclusions of behavioural theory, which states that irrational investor sentiment affects asset pricing levels.

Lemmon and Portniaguina (2006) analyzed the times-series relationship between sentiment and stock returns using the University of Michigan Consumer Sentiment Index and the Conference Board Consumer Confidence Index as measures for investor optimism.

The findings were consistent with the idea that investors seemed to overestimate small stocks relative to large stocks during periods of high confidence and vice versa. 
According to Lemmon and Portniaguina (2006), a possible explanation for small stocks be prone to the influence of sentiment is that such stocks are disproportionately held by individual investors (as opposed to institutions), who are more prone to the influence of sentiment.

The authors also investigated this hypothesis and found that stocks with low institutional ownership exhibited low (high) returns following periods of high (low) sentiment.

Baker and Wurgler (2006) studied how sentiment affected the cross-section of stock returns. They concluded that returns of stocks whose valuation are highly subjective and difficult to arbitrage were constrained by investor sentiment at the beginning of the period. When sentiment was estimated as high, the stocks were attractive to speculators, but unattractive to arbitrageurs - young stocks, small stocks, unprofitable stocks, non-dividend-payer stocks, high volatility stocks, extreme growth stocks and distressed stocks - tended to earn lower subsequent returns.

In their study Baker and Wurgler (2007) investigated whether speculative stocks whose arbitrage was difficult were more sensitive to sentiment. They concluded that when sentiment was low the average future returns of speculative stocks exceeded bond-like stocks returns. When sentiment was high the future returns of speculative stocks was, on average, lower than the returns of the bond-like stocks. Thus, they found that the higher risk stocks, sometimes exhibit low returns, which is inconsistent with classical models of asset pricing.

Although the main objective of the above study focuses on differences in cross-section returns, the authors also found that there was a positive correlation between aggregate market returns and changes in sentiment, if the average of the stocks was affected by sentiment.

Schmeling (2009) examined how the consumer confidence index - as a proxy for investor sentiment - affected stock returns internationally in 18 countries. According to the author, it seems reasonable that sentiment shocks affected stock markets aggregately and not just different subgroups of stocks.

The author also examined how sentiment affects especially countries with low institutional development or countries which are especially prone to herd-like behaviour and overreaction.

Schmeling (2009) found that sentiment had a significantly negative impact on future returns. In general, the results were consistent with the theoretical considerations about the impact of noise traders, and were in accordance with the evidence found in the US market.

The results also revealed some heterogeneity across countries with regard to the sentimentreturn relationship. In Japan, Italy and Germany, for example, the results showed the existence of a strong relationship between sentiment and future returns. However, in countries like Australia, New Zealand or the UK there was a weak or nonexistent relationship between the two variables. The results for the US also revealed that this country cannot be seen as particularly prone to sentiment effects. Sentiment effects on returns seem to be country-specific. Regarding sentiment effects on returns of value stocks and growth stocks, there was some heterogeneity between countries too. 
Schmeling (2009) also examined the extent to which sentiment influenced returns in countries with different cultures. He found that countries that had high levels of collectivism ${ }^{5}$ showed a strong effect of sentiment on stock returns, concluding that countries with a cultural tendency for herding were subject to a strong sentiment-return relationship.

The author suggested that it cannot transfer evidence from the US to other markets and presume that the irrational noise traders affect stock markets in general. Conversely, he found that institutional quality and cultural factors were strong determinants of the sentiment-return relationship. According to this author, high quality market institutions seem to be desirable to mitigate effects of noise trading.

Wang, Keswani and Taylor (2006) studied how sentiment might be useful in forecasting volatility. They found that sentiment had predictive power for future volatility when past returns were included.

Bergman and Roychowdhury (2008) investigated the fact that firms tried to influence sentiment driven expectations, varying their strategic policies on information disclosure. The authors predicted that disclosure policy would be adjusted in response to investor sentiment, with the amount of disclosure negatively associated with the level of sentiment.

The results of this study showed that firms used information disclosure policies to influence investor sentiment. Bergman and Roychowdhury (2008) found that during periods of high sentiment, managers reduced the frequency of long run earnings forecasts, while during periods of low sentiment the frequency of those predictions increased.

Mian and Sankaraguruswamy (2008) found that the response of stock prices to good news increased with sentiment, while the response of stock prices to bad news decreased with sentiment, which was consistent with the hypothesis that the prevailing market sentiment influenced investors' response to firms' announcements in the direction of sentiment. They also found that the price response was more pronounced for stocks that have more subjective valuations and faced limits on arbitrage: small stocks, young stocks, volatile stocks, non-dividend-paying stocks, growth stocks and distressed stocks.

Apart from the studies mentioned, others have also examined the extent to which investor sentiment of a given market might influence the assets of other markets.

Verma and Soydemir (2006) studied the degree to which American individual and institutional investor sentiment affects the UK, Mexico, Brazil and Chile stock markets. The results of this study

\footnotetext{
${ }^{5}$ According to Hofsted (2001), individualism reflects the degree to which people, in a given country, focus on their internal attributes, such as their own abilities, to differentiate themselves from others. So, according to the author, collectivism quantifies the degree to which individuals, in different countries, are prone to act in groups and not as individuals. Chui, Titman and Wei (2010) suggested that differences in collectivist behaviours may be the drivers of investors' tendency to herding.
} 
showed that American institutional investor sentiment had a significant impact on stock returns in the UK and Latin American markets. However, the impact of individual sentiment only had a significant effect in the UK market. Additionally, they found that sentiment effects in the analyzed markets take place at different times, which may represent lower market efficiency.

Chang, Faff and Hwang (2009) studied the impact of American investor sentiment in 38 stock markets over the period of 1977 to 2004 . The objective was to analyze to what extent American sentiment is contagious across global markets.

The results showed the existence of an American sentiment contagion effect in markets outside the US. Future stock returns that were more prone to the sentiment effect decreased following periods of high sentiment.

Regarding the country development level, the results did not show clear evidence that the contagion effect was stronger or weaker in the developed or developing countries.

The authors found that American investor sentiment spread to other markets through the asset holdings of international investors especially for size, book equity/market equity growth and dividend portfolios.

Chang, Faff and Hwang (2009) also found that there was an American investor sentiment contagion in markets outside the US, where the quality of the informational environment of the market was high.

As for the role of the corporate governance environment in explaining the observed levels of contagion, the authors found that good corporate governance contributed to reducing the spread of American investor sentiment to other markets. The results also suggested a strong sentiment contagion effect when corporate governance was poor.

From the study of empirical evidence on the sentiment effects on the stock market an important issue derives: how to measure investor sentiment? There are several proposed measures for this variable. However, not all are free from criticism, and most importantly, none of the existing proposals so far seem to achieve a consensus of most finance researchers. Some of these proposals are discussed in the following section.

\subsection{Sentiment measures}

Sentiment measures can be divided into two groups: explicit measures, when the sentiment indicator is derived directly from investor surveys and implicit measures, when the indicator is obtained from indirect proxies. 
For explicit measures we emphasize the compilation of investment newsletters by Investors Intelligence. In this database, the newsletters are classified into three categories - bullish, bearish and waiting for a correction. These measures were used by Fisher and Statman (2000) for sentiment of the medium-sized investors, by Brown and Cliff (2005) and Glushkov (2005). For example, Brown and Cliff (2005) used the bull-bear spread, which is the difference between the percentage of bullish newsletters and the percentage of bearish newsletters, to measure sentiment.

The Investors surveys - data obtained from the American Association of Individual Investors, also reflect explicit measures and were used by Fisher and Statman (2000) for individual investor sentiment, by Brown and Cliff (2005) and by Verma and Soydemir (2006).

The consumer confidence index has also been used as an explicit sentiment measure. For example, Qiu and Welch (2006), Lemmon and Portniaguina (2006), Bergman and Roychowdhury (2008) and Schmeling (2009) used the consumer confidence index from the University of Michigan (UM) as a sentiment measure. Schmeling (2009) also used the consumer confidence index - data from Directorale General for Economic and Financial Affairs (DG ECFIN).

Among the implicit measures, there are several proposals for sentiment proxies, for example, the mean allocation to stocks in Wall Street strategists' recommended portfolios was the proxy used by Fisher and Statman (2000) for the sentiment of the large investors.

Another example is the closed-end fund discount (CEFD) a measure used by Lee, Shleifer and Thaler (1991) and Hughen and McDonald (2005). The number of new initial public offerings (IPOs), used by Lee, Shleifer and Thaler (1991), the put-call trading volume ratio, used by Wang, Keswani and Taylor (2006), ${ }^{6}$ are proposed sentiment proxies too.

Recently composite indices have been proposed, such as the Glushkov (2005) and Baker and Wurgler (2006) sentiment proxies.

Glushkov (2005) proposed an index composed of the bull-bear spread; the dividend premium (difference of the average market-to-book ratios of payers and non payers); the closed-end fund discount; the percent change in margin borrowing; the ratio of specialists' short sales to total short sales; the net new cash flows of US equity mutual funds; the number and average first-day returns on IPOs.

Baker and Wurgler (2006) used the closed-end fund discount, trading volume as measured by NYSE turnover, the number and average first-day returns on IPOs, the equity share in new issues (share of equity issues in total equity and debt issues) and the dividend premium to construct a composite sentiment index.

\footnotetext{
6 "The put-call trading volume ratio is a measure of market participants' sentiment derived from options and equals the trading volume of put options divided by the trading volume of call options. When market participants are bearish, they buy put options either to hedge their spot positions or to speculate bearishly" (p.112).
} 
The Baker and Wurgler's (2006) sentiment index has been used by other authors, such as Mian and Sankaraguruswamy (2008) and Chang, Faff and Hwang (2009), for example.

As can be seen, there are various proposals for sentiment measures, even though there is no consensus among researchers. The implicit measures have been criticized, particularly because they may be contaminated by fundamentals that influence securities returns.

Moreover, some explicit measures did not correlate with implicit measures as noted by Qiu and Welch (2006).

These authors analyzed two potential proxies for investor sentiment - the CEFD and the Michigan Consumer Confidence Index and tried to validate these proxies against a more direct proxy for investor sentiment from Survey of Investor Sentiment conducted by UBS/Gallup.

Qiu and Welch (2006) argued that, contrary to the consumer confidence index, the CEFD cannot be a good sentiment proxy based on the following arguments: "First, there can be other factors that can influence the CEFD and its changes, as for example, transaction costs, or time-varying liquidity premia and agency costs. Second, the CEFD could be disproportionately held by unusual retail investors, which may not represent ordinary retail investors" (p. 5).

The authors argued that, "intrinsically, the consumer confidence index seems to be a concept similar to investor sentiment. Many investors are likely to be bullish about the economy when they are bulish about the stock market and vice versa. Thus, they considered the possibility of consumer confidence index and investor sentiment must be positively correlated" (p. 7).

Qiu and Welch (2006) found that there was no correlation between the Michigan Consumer Confidence Index and the CEFD. However, the results showed a significant positive correlation between changes in consumer confidence index and the changes in the UBS/Gallup investor sentiment series. However, the authors found that there was no correlation between changes in the investor sentiment series from UBS/Gallup and the changes in the CEFD.

The authors also observed that there was no correlation between Baker and Wurgler's (2006) sentiment index and the consumer confidence index, probably because Baker and Wurgler's (2006) index contains the CEFD.

Thus, the authors suggest that, based on UBS/Gallup investor sentiment survey data, it was not possible to validate the CEFD as a proxy for investor sentiment. In light of the results, Qiu and Welch (2006) believe that the CEFD is inadmissible as a reasonable proxy for investor sentiment. Nevertheless, they argue that the consumer confidence index can be validated as a proxy for investor sentiment, based on UBS/Gallup investor sentiment survey data.

The authors state that "the mechanism which consumer confidence influences financial returns operates neither exclusively through the real underlying economic markets, nor exclusively through the financial markets. Instead, both pathways seem to matter" (p. 27). 
In order to compare their sentiment component of consumer confidence with other measures proposed in the literature Lemmon and Portniaguina (2006) also analyzed the correlations between it and the Baker and Wurgler (2006) sentiment measure and the CEFD. The results were consistent with those of Qiu and Welch (2006). According to the authors, this evidence may indicate that different measures capture some unrelated components of investor sentiment, or perhaps all have gaps regarding the consideration of some important sentiment aspects.

The consumer confidence indexes include both a rational and emotional components (this can represent a valid measure for investor sentiment).

Lemmon and Portniaguina (2006) consider that the confidence index reflects investor sentiment but also the effect of macroeconomic variables. Thus, the authors estimated the regression of the confidence indices on a set of macroeconomic variables. They found that approximately 20 percent of the confidence index was not explained by those variables. Based on these results, the authors considered that the predicted value from the regression is the measure of the fundamental component of consumer confidence and the residuals represented sentiment (optimism or pessimism).

Verma and Soydemir (2006) used a similar methodology to separate the rational from the irrational component of investor sentiment.

Although they do not meet the consensus of most researchers, explicit measures have been used more often to study the impact of investor sentiment on the markets.

\section{Methodology}

To examine whether investor sentiment predicts future aggregate stock market returns and industry indices returns in Portugal, we follow Schmeling (2009) and initially estimate the predictive regression equation of the form:

$$
r_{t+1}^{i}=\alpha_{0}^{i,(1)}+\alpha_{1}^{i,(1)} \cdot \operatorname{Sent}_{t}+\varepsilon_{t+1}^{i,(1)}
$$

Were $r_{t+1}^{i}$ is the monthly return of the aggregate stock market or the industry index at time $t+1$ and Sent $_{t}$ is a proxy for lagged Portuguese investor sentiment.

We later added to the previous relationship a set of macroeconomic factors as control variables and estimate the predictive regression equation of the form: 


$$
r_{t+1}^{i}=\alpha_{0}^{i,(1)}+\alpha_{1}^{i,(1)} \cdot \operatorname{Sent}_{t}+\varphi_{t}^{(1)} \delta^{i,(1)}+\varepsilon_{t+1}^{i,(1)}
$$

The term $\varphi_{t}$ is a macroeconomic factor matrix.

In order to analyze the sentiment effect on future returns across horizons, we jointly estimate regression equation (1) for forecast horizons of $1,3,6$ and 12 months in a system of equations and perform tests of the form $\alpha_{1}^{i,(1)}=0, \alpha_{1}^{i,(3)}=0, \alpha_{1}^{i,(6)}=0, \alpha_{1}^{i,(12)}=0$, i.e., we test whether there is a jointly significant impact at the 1, 3, 6 and 12 months horizon. Similarly, we jointly estimate regression equation (2). So, we estimate the system of regressions equations of the form:

$$
\begin{aligned}
& \left\{\begin{array}{l}
r_{t+1}^{i}=\alpha_{0}^{i,(1)}+\alpha_{1}^{i,(1)} \cdot \text { Sent }_{t}+\varepsilon_{t+1}^{i,(1)} \\
\frac{1}{K} \sum_{K=1}^{3} r_{t+K}^{i}=\alpha_{0}^{i,(3)}+\alpha_{1}^{i,(3)} \cdot \operatorname{Sent}_{t}+\varepsilon_{t+1 \rightarrow t+3}^{i,(3)} \\
\frac{1}{K} \sum_{K=1}^{6} r_{t+K}^{i}=\alpha_{0}^{i,(6)}+\alpha_{1}^{i,(6)} \cdot \operatorname{Sent}_{t}+\varepsilon_{t+1 \rightarrow t+6}^{i,(6)} \\
\frac{1}{K} \sum_{K=1}^{12} r_{t+K}^{i}=\alpha_{0}^{i,(12)}+\alpha_{1}^{i,(12)} \cdot \operatorname{Sent}_{t}+\varepsilon_{t+1 \rightarrow t+12}^{i,(12)} \\
r_{t+1}^{i}=\alpha_{0}^{i,(1)}+\alpha_{1}^{i,(1)} \cdot \operatorname{Sent}_{t}+\varphi_{t}^{(1)} \delta^{i,(1)}+\varepsilon_{t+1}^{i,(1)} \\
\frac{1}{K} \sum_{K=1}^{3} r_{t+K}^{i}=\alpha_{0}^{i,(3)}+\alpha_{1}^{i,(3)} \cdot \operatorname{Sent}_{t}+\varphi_{t}^{(3)} \delta^{i,(3)}+\varepsilon_{t+1 \rightarrow t+3}^{i,(3)} \\
\frac{1}{K} \sum_{K=1}^{6} r_{t+K}^{i}=\alpha_{0}^{i,(6)}+\alpha_{1}^{i,(6)} \cdot \operatorname{Sent}_{t}+\varphi_{t}^{(6)} \delta^{i,(6)}+\varepsilon_{t+1 \rightarrow t+6}^{i,(6)} \\
\frac{1}{K} \sum_{K=1}^{12} r_{t+K}^{i}=\alpha_{0}^{i,(12)}+\alpha_{1}^{i,(12)} \cdot \operatorname{Sent}_{t}+\varphi_{t}^{(12)} \delta^{i,(12)}+\varepsilon_{t+1 \rightarrow t+12}^{i,(12)}
\end{array}\right.
\end{aligned}
$$

Where the variables have the usual meaning.

In order to examine whether US investor sentiment predicts future aggregate stock market returns and industry indices returns, we perform the methodology described above. However, in all the regressions equations we replace the Portuguese investor sentiment by the US investor sentiment. 
The stock market indices used in our study were the $\mathrm{MSCl}$ index for Portugal (proxy for the market) and industrial indices from Euronext: PSI Basic Material; PSI Industrials; PSI Consumer Goods; PSI Consumer Services; PSI Telecommunications; PSI Utilities; PSI Financials; and PSI Technology. Table 1 shows the indices descriptive statistics and their data sources, as well as for the other variables used in our study.

The proxy for Portuguese investor sentiment resulted from applying Lemmon and Portniaguina's (2006) methodology, which allowed us to separate the rational from the emotional component of the EU economic sentiment indicator (ESI). So, we used the residuals of the regression of ESI on a set of macroeconomic factors as a proxy for investor sentiment. We used the ESI instead of the consumer confidence index. First because it covers data on consumer and business confidence, which could allow us to obtain new and important conclusions about the influence of sentiment. Second, given that the consumer confidence index was considered a valid variable to obtain a proxy for investor sentiment [by authors such as Qiu and Welch (2006)], then the use of that index will allow us to test the robustness of the results later. ${ }^{7}$

Similarly, we obtain the proxy for US investor sentiment using the Michigan Consumer Confidence Index as dependent variable.

Following Lam and Ang's (2006) methodology, we obtained macroeconomic factors, from a range of global and domestic macroeconomic variables, ${ }^{8}$ applying the principal component analysis technique with the Varimax factor rotation method. From this methodology three global principal components and three domestic principal components have been identified. ${ }^{9}$ This technique reduces the likelihood of multicollinearity among the variables.

The consideration of global macroeconomic variables as controls, jointly with the domestic ones, was motivated by Lam and Ang's (2006) findings. They verified that global factors were relevant in explaining market returns. ${ }^{10}$

\footnotetext{
${ }^{7}$ Note that the correlation between sentiment proxies obtained from the ESI and from the consumer confidence index is 0.67 .

${ }^{8}$ Table 1 provides a description of the variables used in the construction of factors, as well as their data sources.

${ }^{9}$ Similarly, we performed the same methodology to obtain the US factors from a set of macroeconomic variables (this set include the same categories of the macroeconomic variables that we used for the extraction of the Portuguese factors, and the respective data were obtained from the OECD and FED databases). However, the data description and the results are not included to save space, but are available upon request.

${ }^{10}$ Lam and Ang (2006) found that Portugal was a country whose stock market returns could be explain more by global than by domestic macroeconomic factors.
} 


\subsection{Results}

We start by briefly presenting the main results of the preliminary methodology in extracting the macroeconomic factors and the proxy for investor sentiment, because this constituted the starting point of this study. ${ }^{11}$

Table 2 presents the global and domestic macroeconomic factors extracted by applying the principal component analysis technique and the variables represented by each one.

From the principal component analysis technique three global principal components have been identified. The variables represented in each are similar to those in Lam and Ang's (2006) study except for the third factor, which in the study by these authors represented only the US-PMI. In all, the three factors explain 96 percent of the variance of the nine macroeconomic variables and each factor explains over than 88 percent of the variance of the variables it represents.

With regard to domestic macroeconomic variables, from the principal component analysis technique three domestic principal components have also been identified. The results of this procedure were, in part, consistent with those reported by Lam and Ang (2006), except for the first factor, which in these authors' study represented only imports and net trade balance. Overall, the three factors explain 87 percent of the variance of the eleven macroeconomic variables and each factor explains more than 72 percent of the variance of the variables it represents.

To obtain a proxy for sentiment we regress ESI monthly values on the global ${ }^{12}$ and domestic macroeconomic factors. ${ }^{13}$ Similarly, we perform the same methodology for the consumer confidence index. The regression has an adjusted $\mathrm{R}^{2}$ of about $85-89$ percent depending on the index used as the dependent variable, indicating that a large part of the variation in $\mathrm{ESI} /$ consumer confidence can be explained by economic fundamentals, a similar result to that obtained by Lemmon and Portniaguina (2006). However, approximately $11-15$ percent of the indicator variation is not explained by economic fundamentals. In this sense, we considered the regression residual values a proxy for sentiment. ${ }^{14}$

\footnotetext{
${ }^{11}$ Some results are not included to save space, but are available upon request.

${ }^{12}$ The consideration of global factors was motivated by the fact that Portugal is an open economy. The OECD trade-to-GDPratio (sum of exports and imports divided by GDP) measures a country's "openness" or "integration" in the world economy: In 2008, the value of this indicator for Portugal was 75 percent (last data available at the time of writing in: http://stats.oecd.org/Index.aspx).

At the level of Portugal's Foreign Direct Investment (FDI) in stocks, Eurostat data show that this investment has increased significantly since 1997. In 2008, FDI in stocks, as a percentage of GDP, was 28 percent (last data available at the time of writing in: http://epp.eurostat.ec.europa.eu/portal/page/portal/statistics/search_database).

The results of this regression showed that global factors were statistically significant.

${ }^{13}$ In all regression processes we have used an estimator that is robust to both heteroskedasticity and autocorrelation called HAC (heteroskedasticity autocorrelated consistent) proposed by Newey and West $(1987,1994)$.

${ }^{14}$ Similarly, we obtain the proxy for US investor sentiment using the Michigan Consumer Confidence Index as dependent variable and the American macroeconomic factors as independent variables. The results obtained were consistent with those reported by Lemmon and Portniaguina (2006), but not included to save space.
} 
Given our objective, we estimated the regression equation (1) to the market and to industry indices. Tables 3 and 4 summarize the results.

The results show that sentiment has some predictive power for market returns (although not reported, the regression's adjusted $R^{2}$ is 3.2 percent) and is statistically significant (at the 5 percent level). In line with previous studies, there is a negative relationship between lag sentiment and stock market returns. In other words, following periods of high sentiment market returns decline. In this case, an increase of one point in the sentiment level is associated, on average, with a 0.3 percent decrease in market returns in the following month.

In the regressions of the industry indices, sentiment is only statistically significant in the case of PSI Industrials, PSI Telecommunications and PSI Utilities (at the 10 percent level). In these industries, the capacity for sentiment to anticipate future returns varies between 0.8 and 2.4 percent (values of the regression's adjusted $R^{2}$ ). These results may indicate that these industries may be more vulnerable to the effects of investor sentiment. Following periods of high sentiment, returns in these industries decline. In other industries, sentiment seems to have no predictive power on returns.

Subsequently, we added the macroeconomic factors as control variables ${ }^{15}$ and estimated the regression (2). These results are also shown in tables 3 and 4.

With regard to the aggregate market, the earlier findings remain. In table 3 , the change of adjusted $R^{2}\left(\Delta\right.$ Adj. $R^{2}$ ) denotes the increment of that adjustment measure when sentiment is included in the regression, compared to a specification with only macroeconomic factors. ${ }^{16}$ The results show that sentiment is significantly negative even in the presence of control variables, adding 3.4 percent of predictive power relative to the other predictor variables.

In the industry indices, with the addition of the macroeconomic factors to the respective regressions, sentiment becomes insignificant in predicting the future returns of PSI Industrials and PSI Utilities. However, in the case of PSI Telecommunications sentiment is significantly negative (at the 10 percent level). Even in the presence of control variables, the results show that sentiment has some additional predictive power for PSI Telecommunications returns (1.1 percent).

In order to analyze the effect of sentiment on future returns for forecast horizons of 1, 3, 6 and 12 months, we estimated the system regressions (3) and (4) for aggregate market and industry indices. The results are also listed in tables 3 and 4.

We find, for the aggregate market, that investor sentiment has a negative and statistically significant impact on future returns for all considered forecasting horizons ( 1 to 12 months), even in the presence of control variables. The statistics of the test of the restrictions $\alpha_{1}^{i,(1)}=0, \alpha_{1}^{i,(3)}=0$,

\footnotetext{
${ }^{15}$ With the exception of interest rates, Composite Leading Indicator Index and PMI series, following Lam and Ang (2006), the series of the macroeconomic principal components are transformed into rates of change by the formula $L N\left(P C_{t} / P C_{t-1}\right)$.

${ }^{16}$ The results of that regression are not included to save space, but are available upon request.
} 
$\alpha_{1}^{i,(6)}=0, \alpha_{1}^{i,(12)}=0$ suggest the hypothesis that the sentiment coefficients are equal to zero should be rejected at the significance level of 1 percent.

It is interesting to note that the impact of sentiment on future returns declines for forecast horizon of 12 months. This result may have statistical and economic explications. On the one hand, the existence of some uncorrected correlation may represent a limitation and influence the relevance of the results for longer horizons. In economic terms this would be an expected result. According to Schmeling (2009), the noise trading effect disperses in the long run, since the limits to arbitrage tend to become weaker.

Analyzing the change of the adjusted $R^{2}\left(\Delta A d j . R^{2}\right)$, we found that sentiment continues to add predictive power to macroeconomic factors for future returns for time horizons longer than one month.

Overall, comparing these results with the findings obtained by Schmeling (2009), it seems that the Portuguese aggregate market behaviour is similar to the Spanish and American markets.

The estimation results of systems regressions for industry indices show that investor sentiment only has a negative and statistically significant impact on future returns for forecast horizons of 3,6 and 12 months only for PSI Telecommunications, PSI Utilities and PSI Technology, even in the presence of control variables. The statistics of the test of the restrictions $\alpha_{1}^{i,(1)}=0, \alpha_{1}^{i,(3)}=0, \alpha_{1}^{i,(6)}=$ $0, \alpha_{1}^{i,(12)}=0$ suggests the hypothesis that the sentiment coefficients equal to zero should be rejected at the significance level of 3 percent.

The change of the adjusted $R^{2}\left(\Delta \mathrm{Adj} . \mathrm{R}^{2}\right)$ shows that sentiment continues to add some predictive power to macroeconomic factors for future returns for time horizons longer than one month.

Note that in the case of PSI Technology and PSI Utilities the results of regression (2) showed that sentiment was insignificant in predicting their respective returns; however, this is not the case for forecast horizons of 3, 6 and 12 months. For PSI Technology we found that the sentiment impact on future returns declines for a forecast horizon of 3 months, indicating that possibly the largest impact comes after the first month.

PSI Telecommunications is the index whose behaviour is more similar to the aggregate market.

Again, the results for industry indices may have statistical explanations, insofar as the existence of some uncorrected correlation may represent a limitation and influence the relevance of the results for longer time horizons.

In order to examine whether US investor sentiment predicts future aggregate stock market returns and industry indices returns, we perform the same methodology, but in all the regressions equations we replace the Portuguese investor sentiment by the American investor sentiment.

Overall, we found that US investor sentiment was insignificant in predicting the future aggregate stock market returns and industry returns in Portugal for all considered forecasting horizons ( 1 to 12 months). 


\subsection{Robustness analysis}

In order to check robustness of the results, we applied the methodology described above, but using the regression residuals of the consumer confidence index. Tables 5 and 6 summarize the results.

For the aggregate market, comparing the information in table 5 with table 3 , the findings are similar. The statistics of the test of the restrictions $\alpha_{1}^{i,(1)}=0, \alpha_{1}^{i,(3)}=0, \alpha_{1}^{i,(6)}=0, \alpha_{1}^{i,(12)}=0$, in the case of the proxy for sentiment obtained from the confidence index, suggests the hypothesis that the sentiment coefficients equal to zero should be rejected at the significance level of 1 percent.

Since the consumer confidence index was considered a valid variable to obtain a proxy for investor sentiment [by authors such as Qiu and Welch (2006)], then the results in Table 5 confirm the findings previously presented concerning to predictive power of sentiment on future market returns.

The results in Table 6 show that investor sentiment (obtained from the confidence index) has no predictive power on industry returns, for forecast horizons of 1 month. Generally speaking, this finding confirms the results and considerations presented above except for the case of PSI Telecommunications.

We also verified that investor sentiment has a negative and statistically significant impact on future returns for forecast horizons of 3, 6 and 12 months in the case of PSI Telecommunications and PSI Utilities and for forecast horizons of 6 and 12 months in the case of PSI Technology. The statistics of the test of the restrictions $\alpha_{1}^{i,(1)}=0, \alpha_{1}^{i,(3)}=0, \alpha_{1}^{i,(6)}=0, \alpha_{1}^{i,(12)}=0$, in the case of the proxy for sentiment obtained from the confidence index, in the case these indices, suggests the hypothesis that the sentiment coefficients equal to zero should be rejected at the significance level of 1 percent.

The change of the adjusted $R^{2}\left(\Delta \mathrm{Adj} . \mathrm{R}^{2}\right)$ shows that sentiment continues to add predictive power to macroeconomic factors for future returns for time horizons longer than one month.

For the PSI Telecommunications, PSI Utilities and PSI Technology indices, the largest sentiment impact on future returns occurred for a forecast horizon of 6 months.

Since predictive power of sentiment on future returns was more significant in the market index, we applied the same methodology, but using the PSI 20 as proxy for the aggregate market. The results of this procedure are summarized in table 7 , whose values confirm the above findings.

The robustness checks, in general, confirm the results obtained, which may mean that the sentiment of economic agents in general may be relevant in predicting returns. 


\section{Conclusion}

The presence of noise traders in the market with sentiment correlated and limits on arbitrage constitute some of the arguments in favor of the relevance of investor's psychological factors in capital markets. In this sense, authors such as Fisher and Statman (2000), Shefrin (2001), Brown and Cliff (2005), Baker and Wurgler (2006, 2007), Lemmon and Portniaguina (2006), Schmeling (2009) and Wang , Keswani and Taylor (2006) argue that sentiment can influence the behaviour of securities in the market, and highlight this fact.

However, most of the studies cited analyzed the effect of sentiment on certain stock categories and focus mainly on the US market.

In this context, our paper aims to analyze the effect of investor sentiment in a small stock market - Portugal between September 1997 and April 2009.

The results showed that sentiment had a negative impact on future market returns for forecast horizons of 1 to 12 months, which in general is consistent with the theoretical considerations of the impact of the noise trader behaviour and with the evidence found by Schmeling (2009) for the US and Spain. Therefore, Portugal seems to be a market somewhat prone to the influence of sentiment, which may be a consequence of its high degree of collectivism.

In the industry analysis, we found that PSI Telecommunications was the index that showed a more similar behaviour to the aggregate market. For the other industry indices sentiment just had some predictive power on the future returns of the PSI Utilities and PSI Technology for forecasting horizons longer than 1 month. In this area, the results were interesting in showing that these industries in particular may be more prone to the influence of investor sentiment.

Finally, we don't found a contagious effect of US investor sentiment in Portuguese market and industry returns.

However, we cannot overlook the possibility that the investor sentiment index, used in our analysis, also represents the effect of omitted relevant variables, which is one of this study's limitations.

The reduced period of analysis, in this case due to the availability of data on some of the macroeconomic variables, is another limitation. The choice of these variables may represent yet another limitation. As stated by Lemmon and Portniaguina (2006), the choice of macroeconomic indicators may be criticized. Although we tried to make our information set as large as possible, given the data available, there is always the risk of omitting relevant variables.

In terms of future research, extending the study to other markets could reveal interesting results regarding the characteristics of countries that may be more susceptible to the influence of sentiment. 
The confirmation of the findings that industries like Telecommunications, Utilities and Technology, in particular, may be more susceptible to the influence of investor sentiment and the possible reasons that explain this evidence may also represent a challenge for future research. 


\section{References}

Andrikopoulos, P., 2007, Modern finance vs. behavioral finance: An overview of key concepts and major arguments. Icfai Journal of Behavioral Finance 4, n.ㅇ 2, 53-70.

Baker, M. and Wurgler, J., 2006, Investor sentiment and the cross-section of stock returns, Journal of Finance 61, n.ㅇ 4, 1645-1680.

Baker, M. and Wurgler, J., 2007, Investor sentiment in the stock market, Journal of Economic Perspectives 1, n. 2, 129-151.

Baberis, N., and Shleifer, A., 2003, Style Investing, Journal of Financial Economics 68, n.o 2, 161-199.

Bergman, N. and Roychowdhury, S., 2008, Investor sentiment and corporate disclosure, Journal of Accounting Research 46, n. 5, 1057-1083.

Brown, G. and Cliff, M., 2004, Investor sentiment and the near-term stock market, Journal of Empirical Finance 1, n. 2, 1-27.

Brown, G. and Cliff, M., 2005, Investor sentiment and asset valuation, Journal of Business 78, n.ㅇ 2, 405-440.

Chang, Y., Faff, R. and Hwang, C., 2009, Sentiment contagion, corporate governance, information and legal environments. Available at SSRN: http://ssrn.com/abstract=1359351.

Chui, A., Titman, S. and Wei, K., 2010, Individualism and momentum around the world, Journal of Finance 68, n. 1, 361-392.

Daniel, K., Hirshleifer, D. and Subrahmanyam, A., 1998, Investor psychology and security market under- and overreactions, Journal of Finance 53, n. 6, 1839-1885.

DeBondt, W., 1998, A portrait of individual investor, European Economic Review 42, n.ㅇs 3-5, 831844.

DeBondt, W. and Thaler, R., 1985, Does the stock market overreact?, Journal of Finance 40, n.o 3, 793-805.

DeBondt, W. and Thaler, R., 1987, Further evidence on investor overreaction and stock market seasonality, Journal of Finance 42, n. 0 3, 557-581.

DeBondt, W. and Thaler, R., 1989, A mean reverting walk down Wall Street, Journal of Economic Perspectives 3, n.ㅇ 1, 189-202.

De Long, J., Shleifer, A., Summers, L. and Waldmann, R., 1990, Noise trader risk in financial markets, Journal of Political Economy 98, n.․ 4, 703-338. 
Fama, E., 1970, Efficient capital markets: A review of theory and empirical work, Journal of Finance 25, n.ㅇ 2, 383-417.

Fama, E., 1998, Market efficiency, long-term returns and behavioural finance, Journal of Financial Economics 49, n.o 3, 283-306.

Fisher, K. and Statman, M., 2000, Investor sentiment and stock returns, Financial Analysts Journal 56, ก.ㅇ 2, 16-23.

Glushkov, D., (2005), Sentiment beta. Available at SSRN: http://ssrn.com/abstract=862444.

Hofstede, G., 2001, Culture's Consequences: Comparing Values, Behaviours, Institutions and Organizations across Nations. Sage Publication, Beverly Hills.

Hughen, J. and McDonald, C., 2005, Who are the noise traders?, The Journal of Financial Research 28, n.. 2, 281-298.

Jame, R. and Tong, K., 2009, Retail investor industry herding. Available at SSRN: http://ssrn.com/abstract=1468952.

Jegadeesh, N. and Titman, S., 1993, Returns to buying winners and selling losers: Implications for stock market efficiency, Journal of Finance 48, n. 1, 65-91.

Kaestner, M., 2006, Anomalous price behavior following earnings Surprises: Does representativeness cause overreaction? Finance 27, n. 2, 5-32.

Kahneman, D., Slovic, P. and Tversky, A., 1982, Judgement Under Uncertainly: Heuristics and Biases, Cambridge University Press.

Lam, S. and Ang, W., 2006, Globalization and stock market returns, Global Economy Journal 6, n.o 1, $1-26$.

La Porta, R., Lopez-de-Silanes, F., Shleifer, A. and Vishny, R., 1997, Legal determinants of external finance, Journal of Finance 52, n.ㅇ 2, 1131-1150.

La Porta, R., Lopez-de-Silanes, F., Shleifer, A. and Vishny, R., 1998, Law and Finance, Journal of Political Economy 106, №. 6, 1113-1155.

Lemmon, M. And Portniaguina, E., 2006, Consumer confidence and asset prices: Some empirical evidence, The Review of Financial Studies 19, ํo. 4, 1499-1529.

Lee. C., Shleifer, A. and Thaler, R., 1991, Investor sentiment and closed-end puzzle, Journal of Finance 46, n. 1, 75-109. 
Mian, G. and Sankaraguruswamy, S., 2008, Investor Sentiment and Stock Market Response to Corporate News. Available at SSRN: http://ssrn.com/abstract=1107619.

Newey, W. and West, K., 1987, A simple, positive semi-definite, heteroskedasticity and autocorrelation consistent covariance matrix, Econometrica 55, n. 3, 703-708.

Newey W. and West, K., 1994, Automatic lag selection in covariance matrix estimation, Review of Economic Studies 61, n. 4, 631-653.

Peng, L., and Xiong, W., 2006, investor attention, overconfidence, and category learning, Journal of Financial Economics 80, n.o 3, 563-602.

Qiu, L. and Welch, I., 2006, Investor sentiment measures. Available at SSRN: http://ssrn.com/abstract=589641.

Schmeling, M., 2009, Investor sentiment and stock returns: some international evidence. Journal of Empirical Finance 16, n. 3, 394-408.

Shefrin, H., 2001, On kernels and sentiment. Available at SSRN: http://ssrn.com/abstract=288258.

Shefrin, H. and Statman, M., 1997, Comparing expectations about stock returns to realised returns, Santa Clara University, Working Paper.

Shleifer, A. and Summers, L., 1990, The noise trader approach to finance, Journal of Economic Perspectives 4, n.o 2, 19-33.

Verma, R. and Soydemir, G., 2006, The impact of U.S. individual and institutional investor sentiment on foreign markets, The Journal of Behavioral Finance 7, n.. 3, 128-14.

Wang, Y., Keswani, A. and Taylor, S., 2006, The relationships between sentiment, returns and volatility, International Journal of Forecasting 22, n. 1, 109-123. 


\begin{tabular}{|c|c|c|c|c|c|c|}
\hline \multicolumn{7}{|c|}{ Descriptive statistics } \\
\hline \multirow{10}{*}{$\begin{array}{c}\text { Global } \\
\text { Macro. } \\
\text { Variables }\end{array}$} & & Label & Source & Obs. & Mean & SD \\
\hline & Consumer Price Index (OECD Total) & CPI & $\mathrm{OECD}^{(1)}$ & 190 & 88,409 & 13,618 \\
\hline & Index of Industrial Production (OECD Total) & IPI & OECD ${ }^{(1)}$ & 190 & 91,902 & 9,728 \\
\hline & OECD Assets Reserves (in USD) ${ }^{(2)}$ & IntReserv & $\mathrm{OECD}^{(1)}$ & 190 & $1,3222 \mathrm{E}+12$ & $6,9578 \mathrm{E}+11$ \\
\hline & OECD Composite Leading Indicator Index ${ }^{(3)}$ & CompLead & $\mathrm{OECD}^{(1)}$ & 190 & 100,020 & 2,131 \\
\hline & OECD Exports (in USD) & Exp & $\mathrm{OECD}^{(1)}$ & 190 & $4,4504 \mathrm{E}+14$ & $1,6245 E+14$ \\
\hline & OECD Imports (in USD) & $\operatorname{Imp}$ & OECD ${ }^{(1)}$ & 190 & $4,7233 E+14$ & $1,8828 \mathrm{E}+14$ \\
\hline & US Discount Rate & USDiscRate & FED $^{(4)}$ & 190 & 0,040 & 0,016 \\
\hline & US Federal Funds Rate & USFedRate & FED $^{(4)}$ & 190 & 0,039 & 0,018 \\
\hline & US Purchasing Manager's Index ${ }^{(5)}$ & USPMI & FRB of ST. Louis ${ }^{(5)}$ & 190 & 51,581 & 5,258 \\
\hline \multirow{11}{*}{$\begin{array}{c}\text { Domestic } \\
\text { Macro. } \\
\text { Variables }\end{array}$} & Consumer Price Index & DCPI & $\mathrm{OECD}^{(1)}$ & 190 & 89,424 & 11,939 \\
\hline & Exports (in USD) & DExp & $\mathrm{OECD}^{(1)}$ & 190 & $2,5789 E+12$ & $9,4071 E+11$ \\
\hline & Foreign Exchange Rate (USD-EUR) & DCamb & $\mathrm{CBP}^{(6)}$ & 190 & 0,871 & 0,129 \\
\hline & Government Expenditure (in USD) & Dgov & $\mathrm{CBP}^{(6)}$ & 190 & $2,0857 E+10$ & $1,3940 E+10$ \\
\hline & Imports (in USD) & DImp & $\mathrm{OECD}^{(1)}$ & 190 & $3,9950 E+12$ & $1,5101 \mathrm{E}+12$ \\
\hline & Index of Industrial Production & DIPI & $\mathrm{OECD}{ }^{(1)}$ & 190 & 96,444 & 7,861 \\
\hline & Long Term Interest Rate ${ }^{(7)}$ & Dtxmlp & $\mathrm{OECD}^{(1)}$ & 190 & 0,049 & 0,029 \\
\hline & Monetary Aggregate M3 (in USD) & DM3 & $\mathrm{CBP}^{(6)}$ & 140 & $1,4864 \mathrm{E}+11$ & $4,6073 E+10$ \\
\hline & Private Consumption (in USD) & DCons & $\mathrm{CBP}^{(6)}$ & 172 & $2,2910 E+10$ & $4,6441 E+09$ \\
\hline & Short Term Interest Rate ${ }^{(8)}$ & Dtxcp & $\mathrm{OECD}^{(1)}$ & 190 & 0,059 & 0,025 \\
\hline & Unemployment Rate & DDesemp & $\mathrm{OECD}^{(1)}$ & 190 & 0,063 & 0,014 \\
\hline \multirow{10}{*}{ Indices } & MSCI Portugal Index & PTMSCI & $\mathrm{MSCl}^{(9)}$ & 190 & 0,003 & 0,065 \\
\hline & PSI 20 & PSI20 & $\mathrm{CBP}^{(6)}$ & 190 & 0,004 & 0,062 \\
\hline & PSI Basic Material & PSIBasicMat & $\mathrm{CBP}^{(6)}$ & 111 & 0,004 & 0,056 \\
\hline & PSI Industrials & PSIInd & $\mathrm{CBP}^{(6)}$ & 111 & 0,006 & 0,075 \\
\hline & PSI Consumer Goods & PSIConsGoods & $\mathrm{CBP}^{(6)}$ & 111 & $-0,006$ & 0,065 \\
\hline & PSI Consumer Services & PSIConsServ & $\mathrm{CBP}^{(6)}$ & 111 & $-0,001$ & 0,087 \\
\hline & PSI Telecommunications & PSITelec & $\mathrm{CBP}^{(6)}$ & 111 & $-0,003$ & 0,078 \\
\hline & PSI Utilities & PSIUtilit & $\mathrm{CBP}^{(6)}$ & 111 & 0,003 & 0,061 \\
\hline & PSI Financials & PSIFin & $\mathrm{CBP}^{(6)}$ & 111 & $-0,007$ & 0,067 \\
\hline & PSI Technology & PSITech & $\mathrm{CBP}^{(6)}$ & 111 & $-0,013$ & 0,125 \\
\hline \multirow{3}{*}{ Sent. } & Economic Sentiment Indicator ${ }^{(10)}$ & ESI & DG ECFIN & 190 & 98,898 & 11,049 \\
\hline & Standardized Consumer Confidence Indicator $(\mathrm{CCl})^{(11)}$ & ConsConf & $\mathrm{OECD}^{(1)}$ & 190 & 98,745 & 2,363 \\
\hline & Michigan Consumer Confidence Index & SentUSMich & FRB of ST. Louis ${ }^{(12)}$ & 190 & 90,219 & 11,006 \\
\hline
\end{tabular}

\section{Some details on variables and their sources}

(1) All data from the OECD database were obtained from the website: http://stats.oecd.org/Index.aspx.

(2) "Reserve assets consist of those external assets that are readily available to and controlled by monetary authorities for direct financing of payments imbalances. Reserve assets comprise of monetary gold, Special Drawing Rights (SDRs), reserve position in the Fund, foreign exchange assets (consisting of currency and deposits and securities) and other claims. The IMF determines the value of SDRs daily by summing, in US dollars, the values - which are based on market exchange rates - of a weighted basket of currencies. The basket and weights are subject to revision from time to time." - OECD definition.

(3) "The OECD Composite Leading Indicators (CLI) dataset is a subset of the Main Economic Indicators (MEI) database. The OECD system of CLI was developed to give early signals of turning points of economic activity. This information is of prime importance for economists, businesses and policy makers to enable timely analysis of the current and short-term economic situation. CLIs are calculated for 29 OECD countries, 6 non-member economies and 9 zone aggregates. A country CLI comprises a set of component series selected from a wide range of key short-term economic indicators mainly covered in the MEI database" - OECD definition. 
(4) The US Federal Funds Rate and US Discount Rate data was collected from the Federal Reserve website: http://www.federalreserve.gov/datadownload/.

(5) The PMI is a composite index of five "sub-indicators" (production, new orders from customers, supplier deliveries, inventories, employment), which are extracted through surveys to US purchasing managers. PMI is an important sentiment reading, not only for manufacturing, but also for the economy as a whole. The Institute for Supply Management (ISM) has is responsible for maintaining the PMI. The PMI data was collected from the Economic Research of Federal Reserve Bank of ST. Louis website: http://research.stlouisfed.org/fred2/series/NAPM.

(6) All data from the Central Bank of Portugal (CBP) database were obtained from the website: http://www.bportugal.pt/EstatisticasWEB/.

(7) We used the yield on 10-year Treasury Bonds as a proxy for long-term interest rate.

(8) We used the 3-month Euribor interest rate as a proxy for short-term.

(9) The MSCI Portugal index data was collected from the MSCl website: http://www.mscibarra.com/.

(10) The Directorate General for Economic and Financial Affairs (DG ECFIN) conducts regular harmonized surveys for different sectors of the economies in the EU to provide information for economic surveillance, short term forecasting and economic research. The surveys provide information on a wide range of variables (for example, production, business activity, consumer financial situation, unemployment, savings, among others) which are useful to monitor cyclical developments. The economic sentiment indicator is made from a range of individual components of the industry, services, consumers, construction and retail trade confidence indicators.

The ESI data was collected from the DG ECFIN website: http://ec.europa.eu/economy_finance/db_indicators/surveys/time_series/index_en.htm.

(11) "The $\mathrm{CCl}$ derived from consumer survey results and are measures which are comparable across countries (members and some non-OECD member countries). Comparability has been achieved by careful selection of national indicators, and by smoothing, centring, and amplitude adjusting these series."

"Consumer opinion surveys are carried out to obtain qualitative information for use in monitoring the current economic situation. Typically, they are based on a sample of households and respondents are asked about their intentions regarding major purchases, their economic situation now compared with the recent past and their expectations for the immediate future. The main characteristic of these types of surveys is that instead of asking for exact figures, they usually ask for the direction of change e.g. a question on tendency by reference to a "normal" state. Possible answers are generally of the five point scale type e.g. increase sharply/increase slightly/remain the same/fall slightly/fall sharply. In presenting the results as a time series, only the balance is shown. That is "same" or "normal" answers are ignored and the balance is obtained by taking the difference between percentages of respondents giving favourable and unfavourable answers." In http://stats.oecd.org/.

(12) The Michigan Consumer Confidence Index data was collected from the Economic Research of Federal Reserve Bank of ST. Louis website: http://research.stlouisfed.org/fred2/series/NAPM. 
Table 2

Panel A

Macroeconomic variables with substantive factor loadings for the dominant Global Principal Components

Global Principal Components

$\begin{array}{lll}\text { GPC1 } & \text { GPC2 } & \text { GPC3 }\end{array}$

IPI, CPI, IntReserv, Exp, Imp USFedRate, USDiscRate

CompLead, USPMI

Panel B

Macroeconomic variables with substantive factor loadings for the dominant Domestic Principal Components Domestic Principal Components

DPC1

DPC2

DPC3

DCPI, DDesemp, DCamb, DExp,

DImp, DM3, DGov, DCons

Dtxcp, Dtxmlp

DIPI

mp, DMB, DGov, DCOns


Table 3

Regression results for the models specified in (1), (2), (3) and (4) with aggregate market returns as dependent variable. $\Delta$ Adj. $R^{2}$ denotes the incremental adjusted R-squared when sentiment is included as an aditional regressor in the equation. Asterisks refer to the level of significance: $* * * 1 \%, * * 5 \%, * 10 \%$.

\begin{tabular}{|c|c|c|c|c|c|c|c|c|c|c|c|c|c|c|c|c|c|c|c|c|c|c|c|c|c|c|c|}
\hline \multirow[b]{3}{*}{ Index } & & \multirow{2}{*}{\multicolumn{2}{|c|}{ (1) }} & \multirow{2}{*}{\multicolumn{2}{|c|}{ (2) }} & \multirow[b]{3}{*}{$\begin{array}{c}\Delta \text { Adj. } \\
\mathrm{R}^{2}\end{array}$} & \multicolumn{8}{|c|}{ (3) } & \multicolumn{13}{|c|}{ (4) } \\
\hline & & & & & & & \multicolumn{2}{|c|}{1 Month } & \multicolumn{2}{|c|}{3 Months } & \multicolumn{2}{|c|}{6 Months } & \multicolumn{2}{|c|}{12 Months } & \multicolumn{2}{|c|}{1 Month } & \multicolumn{3}{|c|}{3 Months } & \multicolumn{3}{|c|}{6 Months } & \multicolumn{5}{|c|}{12 Months } \\
\hline & & Coeff. & T-stat & Coeff. & T-stat & & Coeff. & T-stat & Coeff. & T-stat & Coeff. & T-stat & Coeff. & T-stat & Coeff. & T-stat & $\begin{array}{c}\Delta \text { Adj. } \\
R^{2}\end{array}$ & Coeff. & T-stat & $\begin{array}{c}\Delta \text { Adj. } \\
\text { R2 }\end{array}$ & Coeff. & T-stat & & $\begin{array}{c}\Delta \text { Adj. } \\
\mathrm{R}^{2}\end{array}$ & Coeff. & T-stat & $\begin{array}{c}\Delta \mathrm{Adj} . \\
\mathrm{R}^{2}\end{array}$ \\
\hline & Sent. (ESI) & $-0,003$ & $-2,428$ & $* *-0,003$ & $-2,422 * *$ & & $-0,003$ & $-2,303 * *$ & $-0,003$ & $-3,679$ & *** ${ }_{-0,003}$ & $-5,171$ & $* * *-0,002$ & $-4,406$ & $* * *-0,003$ & $-2,311 *$ & ** & $-0,003$ & $-3,790^{* * *}$ & & $-0,003$ & $-6,087$ & *** & & $-0,002$ & $-7,024^{* * *}$ & \\
\hline & GPC & & No & & Yes & & & No & & No & & No & & No & & Yes & & & Yes & & & Yes & & & & Yes & \\
\hline PTMSCI & DPC & & No & & Yes & & & No & & No & & No & & No & & Yes & & & Yes & & & Yes & & & & Yes & \\
\hline & $\Delta$ Adj. $R^{2}$ & & & & & $3,4 \%$ & & & & & & & & & & & $2,8 \%$ & & & $9,1 \%$ & & & & $18,8 \%$ & & & $16,4 \%$ \\
\hline & Obs. & & 138 & & 138 & & & 127 & & 127 & & 127 & & 127 & & 127 & & & 127 & & & 127 & & & & 127 & \\
\hline
\end{tabular}


Table 4

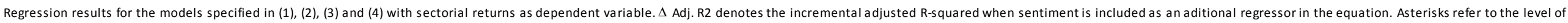

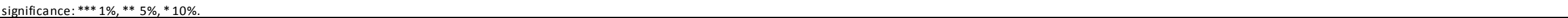

\begin{tabular}{|c|c|c|c|c|c|c|c|c|c|c|c|c|c|c|c|c|c|c|c|c|c|c|c|c|c|c|}
\hline \multirow[b]{3}{*}{ Index } & & \multirow{2}{*}{\multicolumn{2}{|c|}{ (1) }} & \multirow{2}{*}{\multicolumn{2}{|c|}{ (2) }} & \multirow[b]{3}{*}{$\begin{array}{c}\Delta \text { Adj. } \\
\mathrm{R}^{2}\end{array}$} & \multicolumn{8}{|c|}{ (3) } & \multicolumn{12}{|c|}{ (4) } \\
\hline & & & & & & & \multicolumn{2}{|c|}{1 Month } & \multicolumn{2}{|c|}{3 Months } & \multicolumn{2}{|c|}{6 Months } & \multicolumn{2}{|c|}{12 Months } & \multicolumn{2}{|c|}{1 Month } & \multicolumn{4}{|c|}{3 Months } & & Months & & & Months & \\
\hline & & Coeff. & T-stat & Coeff. & T-stat & & Coeff. & T-stat & Coeff. & T-stat & Coeff. & T-stat & Coeff. & T-stat & Coeff. & T-stat & $\begin{array}{c}\Delta \text { Adj. } \\
\mathrm{R}^{2}\end{array}$ & Coeff. & T-stat & $\begin{array}{c}\Delta \text { Adj. } \\
\mathrm{R}^{2}\end{array}$ & Coeff. & T-stat & $\begin{array}{c}\Delta \text { Adj. } \\
\mathrm{R}^{2}\end{array}$ & coeff. & T-stat & $\begin{array}{c}\Delta \text { Adj. } \\
\mathrm{R}^{2}\end{array}$ \\
\hline & Sent. (ESI) & 0,000 & 0,055 & 0,001 & 0,578 & & 0,000 & $-0,072$ & $-0,001$ & $-0,742$ & $-0,001$ & $-1,128$ & $-0,001$ & $1-1,550$ & 0,000 & 0,083 & & 0,000 & $-0,557$ & & $-0,001$ & $-0,928$ & & $-0,001$ & $-1,711 *$ & \\
\hline & GPC & & No & & Yes & & & No & & No & & No & & No & & Yes & & & Yes & & & Yes & & & Yes & \\
\hline PSIBasic & DPC & & No & & Yes & & & No & & No & & No & & No & & Yes & & & Yes & & & Yes & & & Yes & \\
\hline Mat & Adj. $R^{2}$ & & $0,0 \%$ & & $7,8 \%$ & & & $0,0 \%$ & & $0,0 \%$ & & $0,3 \%$ & & $1,4 \%$ & & $2,5 \%$ & & & $13,7 \%$ & & & $24,9 \%$ & & & $54,9 \%$ & \\
\hline & $\begin{array}{l}\Delta \text { Adj. } R^{2} \\
\text { Obs. }\end{array}$ & & 111 & & 111 & $-0,7 \%$ & & 100 & & 100 & & 100 & & 100 & & 100 & $-1,1 \%$ & & 100 & $-0,6 \%$ & & 100 & $-0,2 \%$ & & 100 & $0,8 \%$ \\
\hline & Sent. (ESI) & $-0,002$ & $-1,796 *$ & $-0,002$ & $-1,299$ & & $-0,002$ & $-1,231$ & $-0,002$ & $-2,547^{* *}$ & $-0,001$ & $-1,461$ & $-0,001$ & $1-1,051$ & $-0,002$ & $-1,049$ & & $-0,002$ & $-2,700^{* * *}$ & & $-0,001$ & $-1,467$ & & 0,000 & $\frac{100}{-1,222}$ & \\
\hline & GPC & & No & & Yes & & & No & & No & & No & & No & & Yes & & & Yes & & & Yes & & & Yes & \\
\hline & DPC & & No & & Yes & & & No & & No & & No & & No & & Yes & & & Yes & & & Yes & & & Yes & \\
\hline PSIIInd & $\operatorname{Adj} . R^{2}$ & & $0,8 \%$ & & $13,3 \%$ & & & $0,5 \%$ & & $5,1 \%$ & & $1,1 \%$ & & $0,0 \%$ & & $9,5 \%$ & & & $37,6 \%$ & & & $55,1 \%$ & & & $81,1 \%$ & \\
\hline & $\Delta$ Adj. $R^{2}$ & & & & & $0,0 \%$ & & & & & & & & & & & $0,0 \%$ & & & $3,8 \%$ & & & $0,5 \%$ & & & $0,1 \%$ \\
\hline & Obs. & & 111 & & 111 & & & 100 & & 100 & & 100 & & 100 & & 100 & & & 100 & & & 100 & & & 100 & \\
\hline & Sent. (ESI) & 0,000 & $-0,080$ & 0,001 & 0,383 & & $-0,001$ & $-1,136$ & 0,000 & $-0,05$ & 0,000 & 0,391 & 0,000 & $-0,221$ & $-0,001$ & $-0,808$ & & 0,000 & 0,548 & & 0,001 & 1,577 & & 0,000 & 1,204 & \\
\hline & GPC & & No & & Yes & & & No & & No & & No & & No & & Yes & & & Yes & & & Yes & & & Yes & \\
\hline PSICons & DPC & & No & & Yes & & & No & & No & & No & & No & & Yes & & & Yes & & & Yes & & & Yes & \\
\hline Goods & $\operatorname{Adj} . R^{2}$ & & $0,0 \%$ & & $10,3 \%$ & & & $0,3 \%$ & & $0,0 \%$ & & $0,0 \%$ & & $0,0 \%$ & & $10,8 \%$ & & & $22,8 \%$ & & & $53,6 \%$ & & & $75,6 \%$ & \\
\hline & $\Delta$ Adj. $R^{2}$ & & & & & $-0,8 \%$ & & & & & & & & & & & $-0,4 \%$ & & & $-0,6 \%$ & & & $0,7 \%$ & & & $0,1 \%$ \\
\hline & Obs. & & 111 & & 111 & & & 100 & & 100 & & 100 & & 100 & & 100 & & & 100 & & & 100 & & & 100 & \\
\hline & $\begin{array}{l}\text { Sent. (ESI) } \\
\text { GPC }\end{array}$ & $-0,002$ & $\begin{array}{l}-1,353 \\
\text { No }\end{array}$ & $-0,002$ & $\begin{array}{l}-1,149 \\
\text { Yes }\end{array}$ & & $-0,002$ & $\begin{array}{l}-1,133 \\
\text { No }\end{array}$ & $-0,002$ & $\begin{array}{l}-1,529 \\
\text { No }\end{array}$ & $-0,002$ & $\begin{array}{l}-2,098^{*} \\
\text { No }\end{array}$ & * $-0,001$ & $\begin{array}{l}-1,949 * \\
\text { No }\end{array}$ & $-0,002$ & $\begin{array}{l}-1,047 \\
\text { Yes }\end{array}$ & & $-0,001$ & $\begin{array}{l}-1,486 \\
\text { Yes }\end{array}$ & & $-0,001$ & $\begin{array}{l}-2,460 * * \\
\text { Yes }\end{array}$ & & $-0,001$ & $\begin{array}{l}-2,691 * * * \\
\text { Yes }\end{array}$ & \\
\hline PSI & DPC & & No & & Yes & & & No & & No & & No & & No & & Yes & & & Yes & & & Yes & & & Yes & \\
\hline ConsServ & $\operatorname{Adj} \cdot R^{2}$ & & $0,3 \%$ & & $4,3 \%$ & & & $2,6 \%$ & & $1,3 \%$ & & $3,2 \%$ & & $2,7 \%$ & & $1,5 \%$ & & & $29,7 \%$ & & & $50,9 \%$ & & & $66,2 \%$ & \\
\hline & $\Delta$ Adj. $R^{2}$ & & & & & $-0,3 \%$ & & & & & & & & & & & $0,0 \%$ & & & $-0,3 \%$ & & & $2,4 \%$ & & & $2,1 \%$ \\
\hline & Obs. & & 111 & & 111 & & & 100 & & 100 & & 100 & & 100 & & 100 & & & 100 & & & 100 & & & 100 & \\
\hline & $\begin{array}{l}\text { Sent. (ESI) } \\
\text { GPC }\end{array}$ & $-0,003$ & $\begin{array}{l}-1,785^{*} \\
\text { No }\end{array}$ & $-0,003$ & $\begin{array}{l}\text { li, }^{-1,940}{ }^{*} \\
\text { Yes }\end{array}$ & & $-0,002$ & $\begin{array}{l}-1,378 \\
\text { No }\end{array}$ & $-0,002$ & $\begin{array}{l}-2,120^{* *} \\
\text { No }\end{array}$ & $-0,002$ & $\begin{array}{l}2,440^{*} \\
\text { No }\end{array}$ & F $-0,001$ & $\begin{array}{l}1-2,583^{* *} \\
\text { No }\end{array}$ & $-0,003$ & $\begin{array}{l}-1,527 \\
\text { Yes }\end{array}$ & & $-0,002$ & $\begin{array}{l}-2,093^{* *} \\
\text { Yes }\end{array}$ & & $-0,002$ & $\begin{array}{l}-2,754^{* * *} \\
\text { Yes }\end{array}$ & & $-0,001$ & $\begin{array}{l}-4,6622^{*} \\
\text { Yes }\end{array}$ & \\
\hline & DPC & & No & & Yes & & & No & & No & & No & & No & & Yes & & & Yes & & & Yes & & & Yes & \\
\hline PSITelec & Adj. $R^{2}$ & & $1,4 \%$ & & $6,3 \%$ & & & $0,9 \%$ & & $3,3 \%$ & & $4,7 \%$ & & $5,3 \%$ & & $5,9 \%$ & & & $22,9 \%$ & & & $42,7 \%$ & & & $80,2 \%$ & \\
\hline & $\Delta$ Adj. $R^{2}$ & & & & & $1,1 \%$ & & & & & & & & & & & $1,2 \%$ & & & $2,5 \%$ & & & $3,7 \%$ & & & $4,1 \%$ \\
\hline & Obs. & & 111 & & 111 & & & 100 & & 100 & & 100 & & 100 & & 100 & & & 100 & & & 100 & & & 100 & \\
\hline & Sent. (ESI) & $-0,003$ & $-1,856^{*}$ & $-0,002$ & $-1,547$ & & $-0,002$ & $-1,476$ & $-0,002$ & $-2,661^{* * *}$ & $*-0,003$ & $-4,285^{*}$ & *** $-0,002$ & $2-3,703^{* * *}$ & $-0,002$ & $-1,497$ & & $-0,002$ & $-2,729^{* * *}$ & & $-0,002$ & $-6,511^{* * *}$ & & $-0,002$ & $-6,352^{* * *}$ & \\
\hline & GPC & & No & & Yes & & & No & & No & & No & & No & & Yes & & & Yes & & $-0,002$ & Yes & & $-0,002$ & $\begin{array}{l}\text { Yes } \\
\text { Yes }\end{array}$ & \\
\hline & DPC & & No & & Yes & & & No & & No & & No & & No & & Yes & & & Yes & & & Yes & & & Yes & \\
\hline PSIUtilit & Adj. $R^{2}$ & & $2,4 \%$ & & $15,1 \%$ & & & $1,1 \%$ & & $5,7 \%$ & & $14,7 \%$ & & $11,2 \%$ & & $11,9 \%$ & & & $41,7 \%$ & & & $73,3 \%$ & & & $77,2 \%$ & \\
\hline & $\Delta$ Adj. $R^{2}$ & & & & & $1,2 \%$ & & & & & & & & & & & $1,0 \%$ & & & $3,7 \%$ & & & $11,0 \%$ & & & $8,9 \%$ \\
\hline & Obs. & & 111 & & 111 & & & 100 & & 100 & & 100 & & 100 & & 100 & & & 100 & & & 100 & & & 100 & \\
\hline & Sent. (ESI) & 0,000 & $-0,017$ & 0,001 & 0,709 & & 0,000 & $-0,178$ & $-0,001$ & $-0,590$ & $-0,001$ & $-1,138$ & $-0,001$ & $1-1,678^{*}$ & 0,000 & 0,114 & & 0,000 & 0,083 & & 0,000 & $-0,752$ & & $-0,001$ & $-1,772^{*}$ & \\
\hline & GPC & & No & & Yes & & & No & & No & & No & & No & & Yes & & & Yes & & & Yes & & & Yes & \\
\hline & DPC & & No & & Yes & & & No & & No & & No & & No & & Yes & & & Yes & & & Yes & & & Yes & \\
\hline PSIFin & Adj. $R^{2}$ & & $0,0 \%$ & & $4,1 \%$ & & & $0,0 \%$ & & $0,0 \%$ & & $0,3 \%$ & & $1,7 \%$ & & $7,2 \%$ & & & $29,4 \%$ & & & $44,9 \%$ & & & $53,8 \%$ & \\
\hline & $\Delta$ Adj. $R^{2}$ & & & & & $-0,6 \%$ & & & & & & & & & & & $-1,0 \%$ & & & $-0,8 \%$ & & & $-0,3 \%$ & & & $1,0 \%$ \\
\hline & Obs. & & 111 & & 111 & & & 100 & & 100 & & 100 & & 100 & & 100 & & & 100 & & & 100 & & & 100 & \\
\hline & Sent. (ESI) & $-0,003$ & $-1,14$ & $-0,003$ & $-1,114$ & & $-0,003$ & \begin{tabular}{|c|}
$-0,946$ \\
\end{tabular} & $-0,002$ & $-1,716^{*}$ & $-0,002$ & $-1,804^{*}$ & $-0,002$ & $2-2,275^{* *}$ & $-0,003$ & $-0,896$ & & $-0,002$ & $-1,741^{*}$ & & $-0,002$ & $-2,090^{* *}$ & & $-0,002$ & $-3,220^{* *}$ & \\
\hline & GPC & & No & & Yes & & & No & & No & & No & & No & & Yes & & & Yes & & & Yes & & & Yes & \\
\hline & DPC & & No & & Yes & & & No & & No & & No & & No & & Yes & & & Yes & & & Yes & & & Yes & \\
\hline PSITech & Adj. $R^{2}$ & & $0,0 \%$ & & $0,0 \%$ & & & $0,0 \%$ & & $1,9 \%$ & & $2,2 \%$ & & $4,0 \%$ & & $0,5 \%$ & & & $17,2 \%$ & & & $30,7 \%$ & & & $55,5 \%$ & \\
\hline & $\Delta$ Adj. $R^{2}$ & & & & & $-0,4 \%$ & & & & & & & & & & & $-0,3 \%$ & & & $1,6 \%$ & & & $2,2 \%$ & & & $4,1 \%$ \\
\hline & Obs. & & 111 & & 111 & & & 100 & & 100 & & 100 & & 100 & & 100 & & & 100 & & & 100 & & & 100 & \\
\hline
\end{tabular}


Table 5 - Robustness analysis

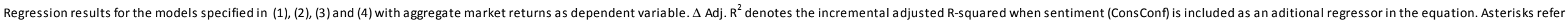
to the level of significance: $* * * 1 \%, * * 5 \%, * 10 \%$.

\begin{tabular}{|c|c|c|c|c|c|c|c|c|c|c|c|c|c|c|c|c|c|c|c|c|c|c|c|c|c|c|}
\hline \multirow[b]{3}{*}{ Index } & & \multirow{2}{*}{\multicolumn{2}{|c|}{ (1) }} & \multirow{2}{*}{\multicolumn{2}{|c|}{ (2) }} & \multirow[b]{3}{*}{$\begin{array}{c}\Delta \text { Adj. } \\
R^{2}\end{array}$} & \multicolumn{8}{|c|}{ (3) } & \multicolumn{12}{|c|}{ (4) } \\
\hline & & & & & & & \multicolumn{2}{|c|}{1 Month } & \multicolumn{2}{|c|}{3 Months } & \multicolumn{2}{|c|}{6 Months } & \multicolumn{2}{|c|}{12 Months } & \multicolumn{2}{|c|}{1 Month } & \multicolumn{4}{|c|}{3 Months } & \multicolumn{2}{|c|}{6 Months } & \multicolumn{4}{|c|}{12 Months } \\
\hline & & Coeff. & T-stat & Coeff. & T-stat & & Coeff. & T-stat & Coeff. & T-stat & Coeff. & T-stat & Coeff. & T-stat & Coeff. & T-stat & $\begin{array}{c}\Delta \text { Adj. } \\
R^{2}\end{array}$ & Coeff. & T-stat & $\begin{array}{c}\Delta \text { Adj. } \\
R^{2}\end{array}$ & Coeff. & T-stat & $\begin{array}{c}\Delta \text { Adj. } \\
R^{2}\end{array}$ & Coeff. & T-stat & $\begin{array}{c}\Delta \text { Adj. } \\
\mathrm{R}^{2}\end{array}$ \\
\hline & Sent. (ConsConf) & $-0,015$ & $-2,364$ & *** $-0,015$ & $-2,230 * *$ & & $-0,013$ & $-1,997^{* *}$ & $-0,013$ & $-3,223$ & *** $-0,013$ & $-4,306$ & $* * *-0,010$ & $-3,838$ & $* * *-0,014$ & $-2,208$ & $* *$ & $-0,015$ & $-3,755 * * *$ & & $-0,014$ & $-5,219 * * *$ & & $-0,010$ & $-5,385 * * *$ & \\
\hline & GPC & & No & & Yes & & & No & & No & & No & & No & & Yes & & & Yes & & & Yes & & & Yes & \\
\hline PTMSCI & DPC & & No & & Yes & & & No & & No & & No & & No & & Yes & & & Yes & & & Yes & & & Yes & \\
\hline & $\Delta$ Adj. $R^{2}$ & & & & & $2,4 \%$ & & & & & & & & & & & $2,4 \%$ & & & $8,9 \%$ & & & $14,5 \%$ & & & $10,7 \%$ \\
\hline & Obs. & & 138 & & 138 & & & 127 & & 127 & & 127 & & 127 & & 127 & & & 127 & & & 127 & & & 127 & \\
\hline
\end{tabular}


Table 6 - Robustness analysis

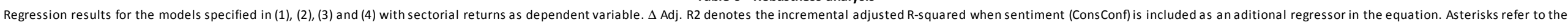

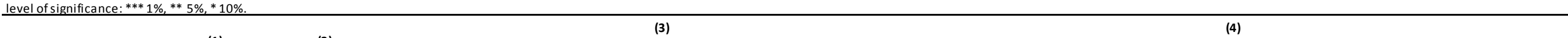

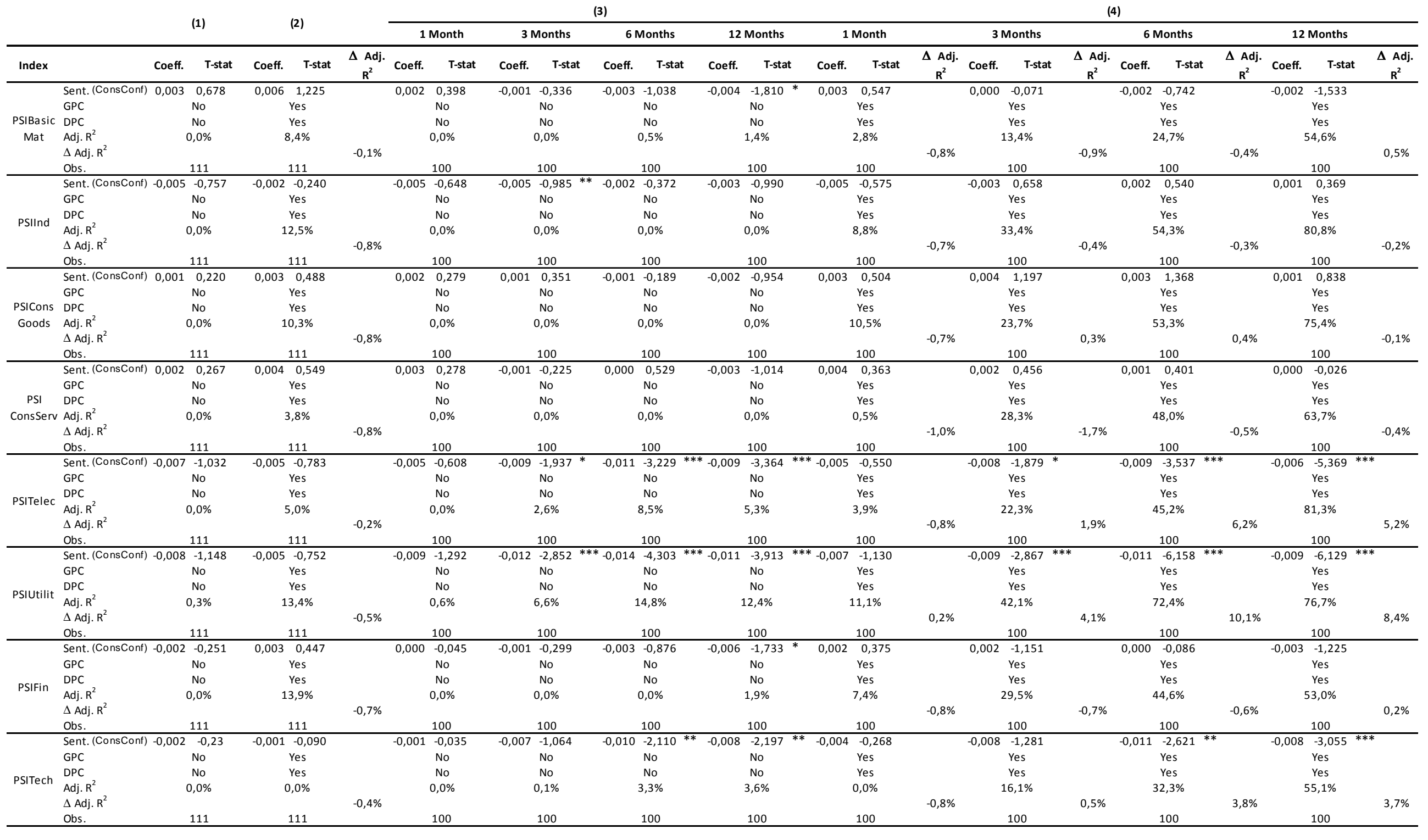


Table 7 - Robustness analysis

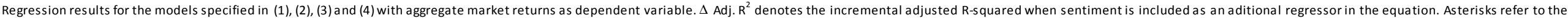
level of significance: $* * * 1 \%, * * 5 \%, * 10 \%$.

\begin{tabular}{|c|c|c|c|c|c|c|c|c|c|c|c|c|c|c|c|c|c|c|c|c|c|c|c|c|c|c|c|}
\hline \multirow[b]{3}{*}{ Index } & & \multirow{2}{*}{\multicolumn{2}{|c|}{ (1) }} & \multirow{2}{*}{\multicolumn{2}{|c|}{ (2) }} & \multirow[b]{3}{*}{$\begin{array}{c}\Delta \text { Adj. } \\
\mathrm{R}^{2}\end{array}$} & \multicolumn{8}{|c|}{ (3) } & \multicolumn{13}{|c|}{ (4) } \\
\hline & & & & & & & \multicolumn{2}{|c|}{1 Month } & \multicolumn{2}{|c|}{3 Months } & \multicolumn{2}{|c|}{6 Months } & \multicolumn{2}{|c|}{12 Months } & \multicolumn{2}{|c|}{1 Month } & \multicolumn{4}{|c|}{3 Months } & \multicolumn{2}{|c|}{6 Months } & \multicolumn{5}{|c|}{12 Months } \\
\hline & & Coeff. & T-stat & Coeff. & T-stat & & Coeff. & T-stat & Coeff. & T-stat & Coeff. & T-sta & Coeff. & T-sta & Coeff. & T-stat & $\begin{array}{c}\Delta \text { Adj. } \\
R^{2}\end{array}$ & Coeff. & T-stat & $\begin{array}{c}\Delta \text { Adj. } \\
\mathrm{R}^{2}\end{array}$ & Coeff. & T-stat & & $\begin{array}{c}\Delta \mathrm{Adj} . \\
\mathrm{R}^{2}\end{array}$ & Coeff. & T-stat & $\begin{array}{c}\Delta \text { Adj. } \\
\mathrm{R}^{2}\end{array}$ \\
\hline \multirow{5}{*}{ PSI 20} & Sent. (ESI) & $-0,003$ & $-2,155$ & ** $-0,003$ & $-2,330^{* *}$ & & $-0,002$ & $-1,903 *$ & $-0,003$ & $-3,523$ & $* * *-0,002$ & $-3,808$ & $* * *-0,001$ & $-2,666$ & $* * *-0,002$ & $-1,879 *$ & & $-0,003$ & $-3,623 * * *$ & & $-0,002$ & $-4,512$ & $* * *$ & & $-0,002$ & $-4,724^{* * *}$ & \\
\hline & GPC & & No & & Yes & & & No & & No & & No & & No & & Yes & & & Yes & & & Yes & & & & Yes & \\
\hline & DPC & & No & & Yes & & & No & & No & & No & & No & & Yes & & & Yes & & & Yes & & & & Yes & \\
\hline & $\Delta$ Adj. $R^{2}$ & & & & & $2,4 \%$ & & & & & & & & & & & $1,9 \%$ & & & $8,9 \%$ & & & & $10,6 \%$ & & & $7,0 \%$ \\
\hline & Obs. & & 138 & & 138 & & & 127 & & 127 & & 127 & & 127 & & 127 & & & 127 & & & 127 & & & & 127 & \\
\hline
\end{tabular}

